Article

\title{
EduSciFIT: A Computer-Based Blended and Scaffolding Toolbox to Support Numerical Concepts for Flipped Science Education
}

\author{
David González-Gómez ${ }^{\mathbb{D}}$ and Jin Su Jeong *(D) \\ Department of Science and Mathematics Education, Training Teaching School, University of Extremadura, \\ Avd. de la Universidad s/n, 10004 Cáceres, Spain; dggomez@unex.es \\ * Correspondence: jin@unex.es
}

Received: 29 April 2019; Accepted: 20 May 2019; Published: 27 May 2019

\begin{abstract}
In education, the use of information, computers, and the Internet as a form of blended technology has been receiving increased attention and consideration. Additionally, increasing attention is being paid toward a scaffolding mechanism that can be integrated into science classrooms in order to solve technological challenges. This work describes a computer-based blended and scaffolding learning toolbox to support numerical concepts for flipped science education, particularly one which is developed and implemented in a MATLAB environment and framed in Adobe Captivate 6 as a HTML5-based e-Learning application, which can be used for science laboratory exercises. This toolbox, named SciEduFIT, is one of the blended and scaffolding learning systems available for use in science education. Through this toolbox, students can acquire the skills to establish the numerical concepts in a flipped science classroom. A survey was conducted to measure the suitability of the proposed toolbox, specifically A to E screens of SciEduFIT. The positive results of the survey indicate that this novel toolbox should be introduced into science classrooms in order to supplement other existing tools currently in use in the area of flipped science education. Therefore, the research shows a general positive perception of the toolbox and highlights the feasibility of the toolbox to achieve significant science learning.
\end{abstract}

Keywords: science education; laboratory; flipped classroom; new technology teaching; computer-aided learning; scaffolding; MATLAB

\section{Introduction}

\subsection{Computer-Based Learning Environment}

During the last decade, the use of information, computers, and the Internet as a form of blended technology has received increased attention. Indeed, considerable attention has been given toward the use of blended technology as a type of scaffolding mechanism and great efforts have been made to develop and implement various integrative tools for (science) education [1-3]. Yet, the core pedagogy behind the teaching and learning in (science) education has not strongly transformed. In the digital age, while dynamic learning environments are quite engaging, their integration into the classroom is still quite challenging for many teachers $[4,5]$. In the context of the digital era, computer-aided learning (CAL) systems are considered to be a form of instructional channel for (science) education. These systems can be easily implemented into educational programs and can be utilized by students without restrictions of time and/or location [6,7]. In fact, online and virtual courses of collaborative web tools, such as Moodle or WebCT, are already used in many universities and educational institutions [8,9]. Alongside these web tools, educators can use user-friendly coding schemes and interactive e-learning or m-learning tools in order to implement and develop ad-hoc software or applications. These 
applications can support and reinforce the concepts that students have previously been exposed to through lectures and/or textbooks, particularly in subjects in which the contents of mathematical and numerical calculations are applied to science education [10-12]. Still, only a few applications among a great variety of CAL systems have shown the ability to meaningfully connect and interact with science education. These systems have experiential learning environments, although the fast growth of computer sciences has permitted a great diversity in the implementation of CAL systems. Traditional blended and scaffolding studies, however, are only focused on particularly computer-embedded prompting [13].

\subsection{Blended and Scaffolding Learning}

Online and blended learning have become commonplace in 21st century higher education [14-17]. The literature review of Larreamendy-Joerns and Leinhardt showed that there have been two corresponding movements in educational settings: the integration of online teaching and learning into everyday practices and the progressively outstanding role of the (science) education programs in universities [15]. Talent-Runnels et al. reviewed class settings, learners' consequences, learners' aspects, and institutional and administrative features [16]. Along with online and blended learnings, scaffolding is a teaching/learning model that can be used to help a teacher, an expert, or a more capable fellow to assist a student, allowing the student to work towards being able to solve a problem independently [18-20]. The Zone of Proximal Development (ZPD), the concept proposed by Vygotsky, describes how students can finish assignments by transitioning from their current ability to their potential ability after accepting the assistance and support offered by scaffolding. In the context of ZPD, the scaffoldings provide enough information to the learners to allow them to make progress $[18,21]$. Consequently, the learners can learn at their own pace and can achieve their own individual learning goals. Moreover, students tend to be more satisfied with training conducted through online courses. These online courses recognize that asynchronous and seamless communication appears to enable students to engage in in-depth evaluations of the material and to subsequently communicate their findings to others [16]. However, none of these somewhat recent literature reviews and further analyses directly focus on the evaluation process. That is of interest and significance because the online and web-enhanced classes and courses provide many additional opportunities for students to actively reflect upon their knowledge and understanding. They are developed throughout the formative assessment and valuation process [22].

\subsection{Flipped Classroom}

A growing number of studies have indicated that traditional science classes do not offer the most effective learning methods for students, although this has been the typical manner in which higher education courses have instructed students during recent years $[3,10,23,24]$. Learning, however, must not be considered as a mere transfer and delivery of knowledge to learners. Students must learn how to use this knowledge and put it into practice through a more student-centered learning environment. To overcome these challenges and difficulties, the flipped classroom model has been recently introduced as a new instructional methodology $[10,25,26]$. This classroom methodology intends to provide enough in-class time for students to complete classroom activities and seeks a constructivist and more active form of learning [27]. For instance, the flipped classroom provides lectures and classes to students at home in the format of video lecture materials together with written materials and assessments via online quizzes and tasks [26,28]. As a result, in actual in-class time, more student-centered learning activities can occur, lessons can be made more interactive and collaborative, and students can be allowed more in-class time to share specific questions $[29,30]$. Thus, a flipped classroom can be considered as a combination of both traditional and online and blended education schemes that are used in- and out-of-class time in order to allow for more effective learning possibilities and perspectives [26]. In particular, it can assign more responsibility in the process of learning to students than to instructors [25]. Therefore, to accomplish better learning results in science 
education, the teaching should focus on the process of science itself by fostering inquiry-based learning, encouraging more student-centered and hands-on science tasks, and establishing cooperative learning environments [31,32].

\subsection{Research Objective and Process}

We propose a computer-based blended and scaffolding learning toolbox to strengthen numerical concepts for flipped science education. This toolbox was developed in the MATLAB (The MathWorks, Inc., Natick, MA, USA) environment and was framed in Adobe Captivate 6 (Adobe Inc., Mountain View, CA, USA) as an HTML5-based e-learning application to be used for a laboratory session. This toolbox requires different functions to process the calculations required to create a numerical concept of instrumental calibration and quality considerations of a laboratory experiment. This toolbox, named EduSciFIT, was used as a blended and scaffolding learning system. To examine how and to what extent students would benefit from the proposed new toolbox, beyond what is being presently used in a laboratory exercise, a survey was administered to 43 professionals to determine the suitability of toolbox proposed to provide reliable results.

The remainder of this paper is structured as follows. Section 2 outlines our materials and methods, defining the different methods related to this research. Section 3 describes the toolbox and outlines survey data set results that were obtained from the application of a computer-aided blended and scaffolding learning toolbox, its statistical survey analysis, and a discussion of the proposed objectives. Finally, our conclusions are described in Section 4.

\section{Materials and Methods}

\subsection{Educational Framework}

The toolbox for numerical concepts was applied in a general science course, required in the sophomore year of the Primary Education bachelor degree in the Training Teaching School of the University of Extremadura (Cáceres, Spain). The general science course is a compulsory subject of the bachelor's degree in Primary Education. Thus, this toolbox can be used in scripted laboratory classes after theoretical lectures. Here, students have the chance to practice their observational skills and establish links between theory and practice. A total of 88 students enrolled in this course, with their specific demographic information provided in Table 1 . This table provides the sample distribution of a primary education group that was actually using the suggested toolbox for numerical concepts, known as EduSciFIT.

Table 1. Demographic information of the 88 students using the proposed toolbox.

\begin{tabular}{ccc}
\hline \multicolumn{2}{c}{ Item } & Course \\
\hline Male & $65 \%$ \\
Female & $35 \%$ \\
Age (years) & 21 \\
Grade Point Average (GPA) & 6.95 \\
& Social Science & $63 \%$ \\
& Science & $18 \%$ \\
Educational Background & Arts & $5 \%$ \\
& Technology & $3 \%$ \\
& Others & $11 \%$ \\
\hline
\end{tabular}

In the context of computer technology, the toolbox's use in science education has been considerably studied and revised. For example, according to the review by Rutten et al., the computational tools' use in science classrooms can produce better learning results and outcomes while students have the opportunity to exercise inquiry-based tasks [33]. With the computational tools used in science teaching, students can discover theoretical situations, which can be interrelated with a simplified type of a 
process, can alter the time-scale of occasions and real tasks, and can resolve problems in a realistic setting without pressure.

\subsection{Toolbox Description, EduSciFIT}

To accomplish the objectives established, an innovative computer toolbox was developed and implemented in MATLAB and framed in Adobe Captivate 6 as an HTML5-based e-learning application to be used in laboratory sessions. EduSciFIT was developed to offer students with a tool that helps them to comprehend the main numerical concepts in science education through self-practice and experimentation. The target students of this toolbox are undergraduate students enrolled in science education. The mathematical terms and equations required for these proposed calculations are determined in statistical texts $[34,35]$ and are summarized in Table 2.

Table 2. Mathematical expressions/equations list required for EduSciFIT to calculate numerical concepts, regression line for external standard, and standard addition method.

\begin{tabular}{|c|c|}
\hline Equation & Function \\
\hline$m=\frac{\sum_{i=1}^{n}\left[\left(x_{i}-\bar{x}\right)\left(y_{i}-\bar{y}\right)\right]}{\sum_{i=1}^{n}\left(x_{i}-\bar{x}\right)^{2}}$ & Regression line slope in unweighted fit \\
\hline$s_{y / x}=\sqrt{\frac{1}{n-2}} \sum_{i=1}^{n}\left(y_{i}-\hat{y}_{i}\right)^{2}$ & Regression line standard error in unweighted fit \\
\hline$s_{m}=s_{y / x} \sqrt{\frac{1}{\sum_{i=1}^{n}\left(x_{i}-\bar{x}\right)^{2}}}$ & Standard deviation slope in unweighted fit \\
\hline$s_{b}=s_{y / x} \sqrt{\frac{\sum_{i=1}^{n} x_{i}^{2}}{n \sum_{i=1}^{n}\left(x_{i}-\bar{x}\right)^{2}}}$ & Intercept Standard deviation in unweighted fit \\
\hline$s_{x}=\frac{s_{y / x}}{m} \sqrt{\left(\frac{1}{M}+\frac{1}{n}\right)+\frac{\left(y_{i}-\bar{y}\right)^{2}}{m^{2} \sum_{i=1}^{n}\left(x_{i}-\bar{x}\right)^{2}}}$ & Standard deviation prediction in unweighted fit \\
\hline$m_{w}=\frac{\sum_{i=1}^{n} w_{i}\left(x_{i}-\bar{x}_{w}\right)\left(y_{i}-\bar{y}_{w}\right)}{\sum_{i=1}^{n} w_{i}\left(x_{i}-\bar{x}_{w}\right)^{2}}$ & Regression line slope in weighted fit \\
\hline$s_{(y / x)_{w}}=\sqrt{\frac{1}{n-2} \sum_{i=1}^{n} w_{i}\left(y_{i}-\hat{y}_{i}\right)^{2}}$ & Regression standard error in weighted fit \\
\hline$s_{m w}=s_{(y / x)_{w}} \sqrt{\frac{1}{\sum_{i=1}^{n} w_{i}\left(x_{i}-\overline{x_{w}}\right)^{2}}}$ & Intercept standard deviation in weighted fit \\
\hline$s_{b w}=s_{(y / x)_{w}} \sqrt{\frac{\sum_{i=1}^{n} w_{i} x_{i}^{2}}{n \sum_{i=1}^{n} w_{i}\left(x_{i}-\bar{x}_{w}\right)^{2}}}$ & Intercept standard deviation in weighted fit \\
\hline$s_{x w}=\frac{s_{(y / x)_{w}}}{m} \sqrt{\left(\frac{1}{M w}+\frac{1}{\sum_{i=1}^{n} w_{i}}\right)+\frac{\left(y_{i}-\overline{y_{w}}\right)^{2}}{m^{2} \sum_{i=1}^{n} w_{i}\left(x_{i}-\bar{x}\right)^{2}}}$ & Prediction standard deviation of in weighted fit \\
\hline
\end{tabular}

$M$ is the number of repetitions of the problem sample analysis; $n$ is the entire number of points employed to analyze the regression line, $w_{i}=1 / s^{2}{ }_{y i}$; and $w_{0}$ is an appropriate weighting feature to the weight of $y$.

A screenshot of EduSciFIT is shown in Figure 1. The EduSciFIT's screenshot contains three different parts. The first part is dedicated to the experimental data inputs (experimental data part) along with three sub-parts: standard data files, unknown data files, and exercises generator. The second part aims to evaluate the quality of the numerical and analytical method (analytical quality parameters part). The third part completed numerical and analytical tests, which includes a test to compare two different calibrations' and prediction abilities' slopes for two different methods. Thus, EduSciFIT tool includes an interactive tutorial and a user manual. In the tutorial part, students can study and learn how to install the application. In the tutorial, different sections of the toolbox are examined. Students must follow the work flow suggested in the tutorial to validate a numerical exercise. In the user manual, a demo-simulation is provided to assist with understanding the contents implemented in the application. 


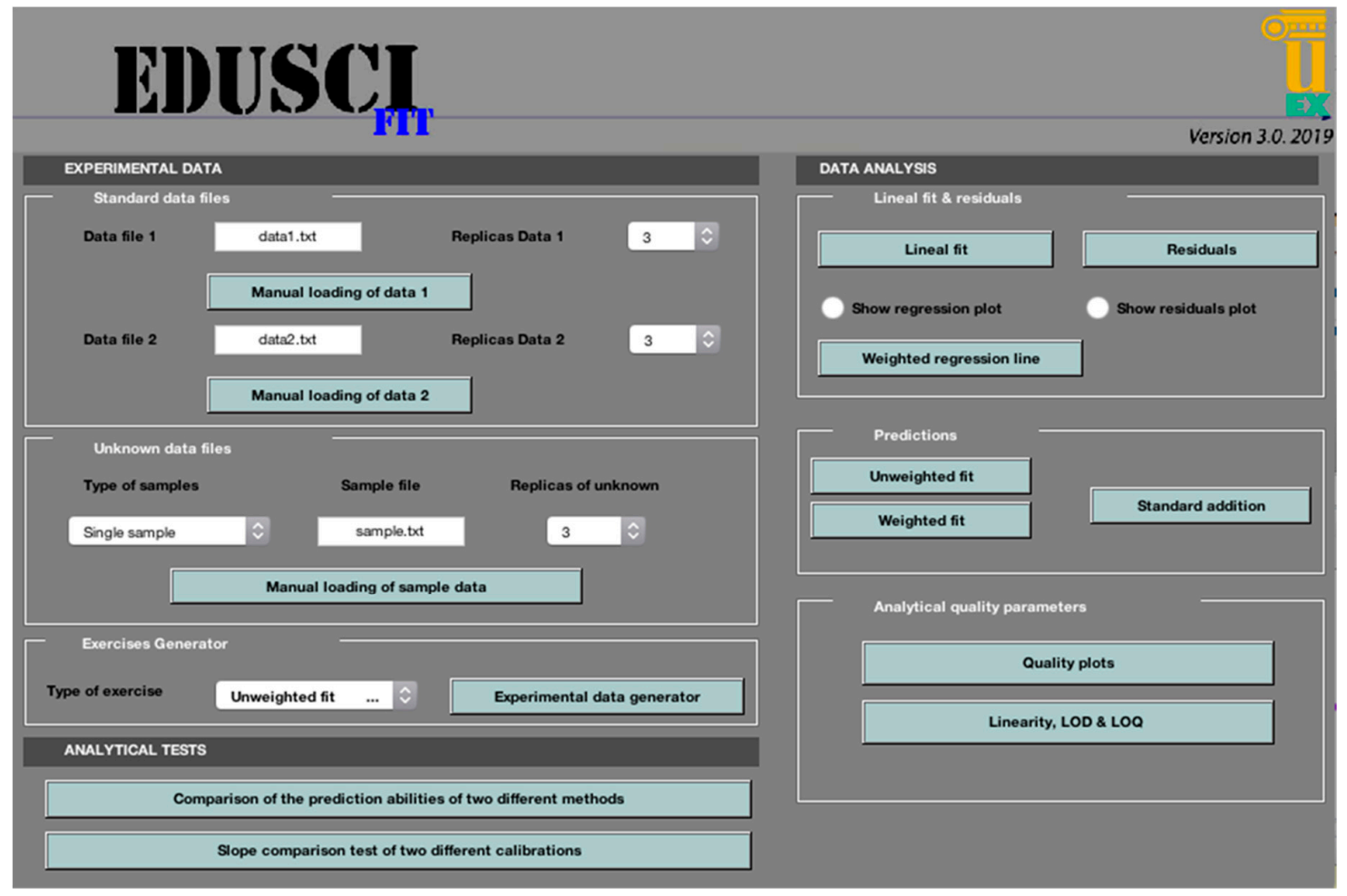

Figure 1. The main screen image of EduSciFIT.

\subsection{Survey Modeling and Description}

We gathered a total of 43 answers from the questionnaire-based survey. All the study participants worked as educators, professors, authorities, or researchers. The vast majority of the participants (over 93\%) actually deal with educational and practical problems in which the application of this tool can be of use. The questionnaire had three parts. First, it asks about the participants' background (positions and work fields). Second, it asks about the participants' perception of the suitability of proposed toolbox for use in a laboratory session of flipped science education. Users were asked to answer, on a five-point Likert scale, how likely they would be to use the EduSciFIT toolbox in their science education courses to reinforce numerical concepts in a flipped learning environment. Users must select at least one of the answers: 'very likely' to 'very unlikely' after using the application and each different possible screen, as shown in the discussion section. The reliability of the Likert-type scale was checked by the Cronbach's $\alpha$ (0.78). Finally, the participants also had the opportunity to explain their opinions in a free-form text space for each implemented screen and clarified their opinions for at least one screen $(79.3 \%)$. Their opinions were post-coded for delivering more common and standard interpretations for the toolbox's suitability. Third, it asked for the participants' additional information so they could be notified of the study results and conclusions.

The application and the survey were administered to all participants through the course website and email. Participants were asked to complete the survey after using the application in all the possible screens or situations. Their participation in the study was voluntary and no personal information was recorded.

\section{Results and Discussion}

The final results of the survey provided feedback about the suitability of the EduSciFIT toolbox for numerical concepts, as a computer-aided blended and scaffolding learning platform for flipped science education. This work is implemented in an ad-hoc MATLAB environment and framed in Adobe Captivate 6 as a HTML5-based e-learning application to be used for laboratory sessions. Then, with the post-task questionnaire survey, we analyzed the information and measurements to assess 
the suitability of the toolbox for science classes. The results reflect the main patterns to address a computer-aided blended and scaffolding learning toolbox in order to reinforce numerical concepts for flipped science education.

\subsection{Experimental Data Inputs}

Figure 2 depicts three screenshots of the first part of the toolbox that are dedicated to the inputs of the experimental data obtained by the students from their laboratory activities. Here, students can introduce the experimental data to the system along with the standard data and unknown data files (Figure 2a). This first part also includes the "exercise generator" tool, which is activated by clicking the "Exercise generator" option shown in the bottom part of this first screen. The exercise generator section provides students with different exercises. Text and experimental data are required to put all the possibilities of EduSciFIT into practice and to reinforce the students' learning. The "Example generator" part starts first with the "Unweighted fit", "Standard addition", and "Comparison of two regression lines" options (Figure $2 b, c)$. All the example information is registered along with the different files needed to run the software. With this simple and essential information, students can have a first impression about how well the experimental points align in a straight line. These statistical and numerical parameters are more correlated with the mathematical expression of the linear regression.

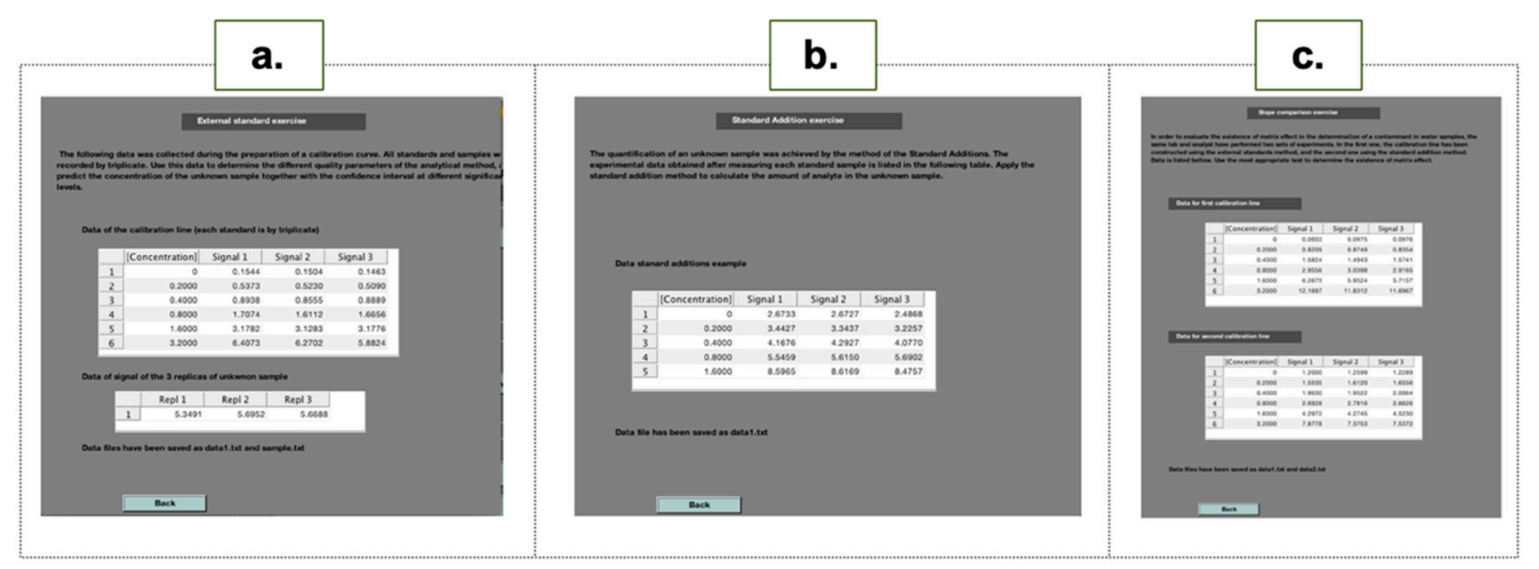

Figure 2. Screenshots of the different exercises that EduSciFIT generates automatically to practice with (a) External standard, (b) Standard addition, and (c) Slope comparison exercises.

\subsection{Quality of the Numerical and Analytical Method}

Figure 3 depicts a screenshot of the second part of the toolbox that is dedicated to the quality of numerical and analytical method. Here, students can calculate the numerical and quality parameters needed to define an analytical application by means of a regression line (parameters such as slope, intercept, accuracy, regression coefficient, and regression error, among others). To provide a graphical view for students, EduSciFIT can display the "Quality plots", as shown in Figure 3. In this figure, to create a straight line, lineal regression, and residual errors plot, the mathematical fit of the experimental data is sourced from the two upper plots. At the preferred signification level, the precision curve and the confidence intervals can be represented by the two bottom plots. Also, the residual error plot displays the significant information about the way in which the errors in $y$ are assigned. Therefore, this section acquires information about whether a weighted or unweighted lineal regression has to be used.

Figure 3 was completed with numerical results, as shown in Figure 4. This figure provides a screenshot of the software part that is used to assess the quality of the analytical method. Here, students can acquire the analytical quality parameters from the linearity, analytical sensitivity, Limit of Detection (LOD), and Limit of Quantification (LOQ). Generally, the detection limit of a method indicates the concentration that can be distinguished from the instrument signal. Therefore, LOD is 
meaningfully different from the blank or background signal [35]. In EduSCiFIT, students can determine the differences in LODs when different possibilities of false positive or negative errors are selected. The smallest concentration or absolute amount of an analyte, LOQ, can be consistently decided, which is considered 10 times higher than the standard deviation of a blank sample signal. In this figure, the described information allows deciding if the method is appropriate to discover the unknown samples with comparable concentrations or count the unknown samples with low concentrations on the basis of LOD and LOQ weights.

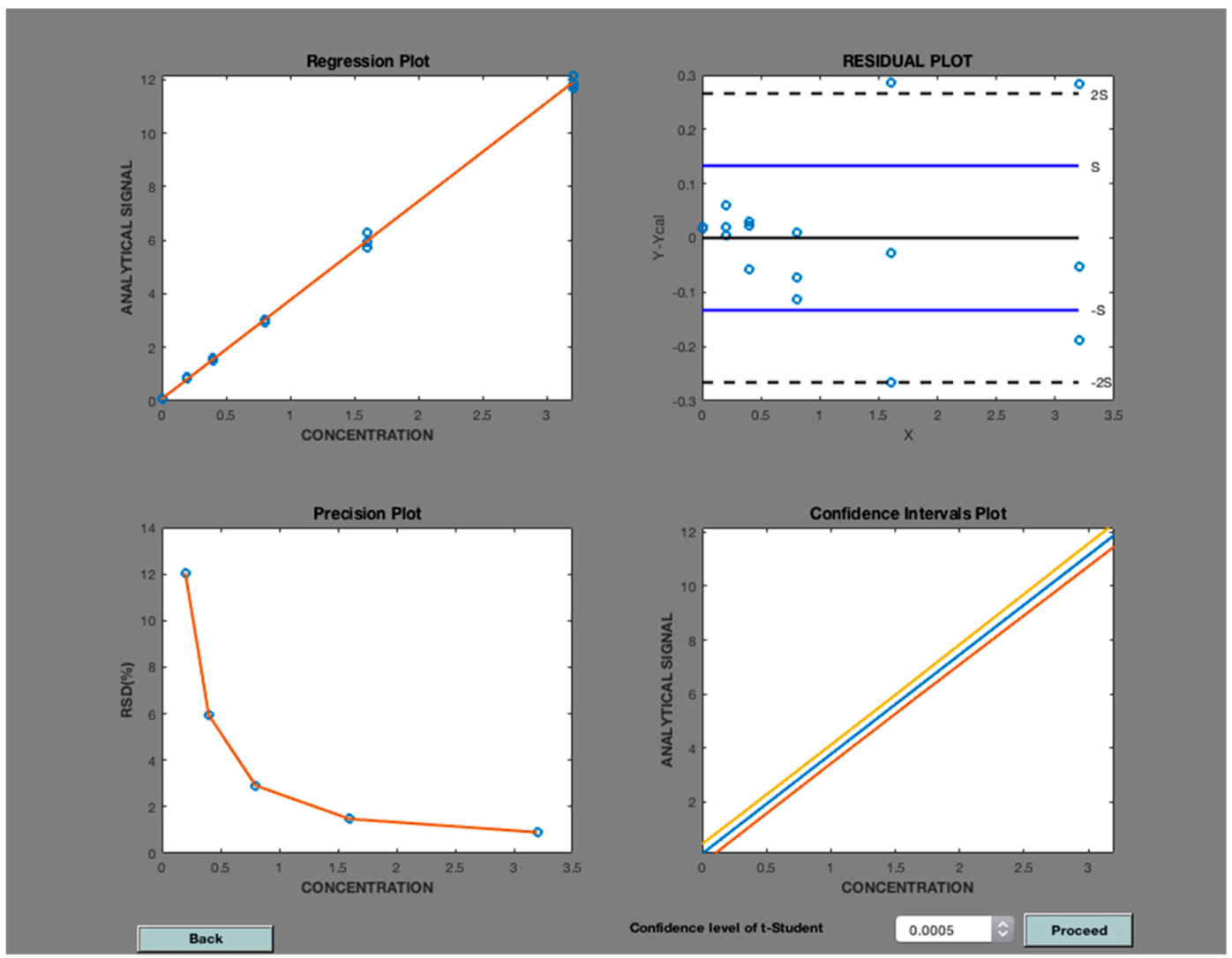

Figure 3. Screenshot of EduSciFIT displaying the quality parameters of an analytical method.

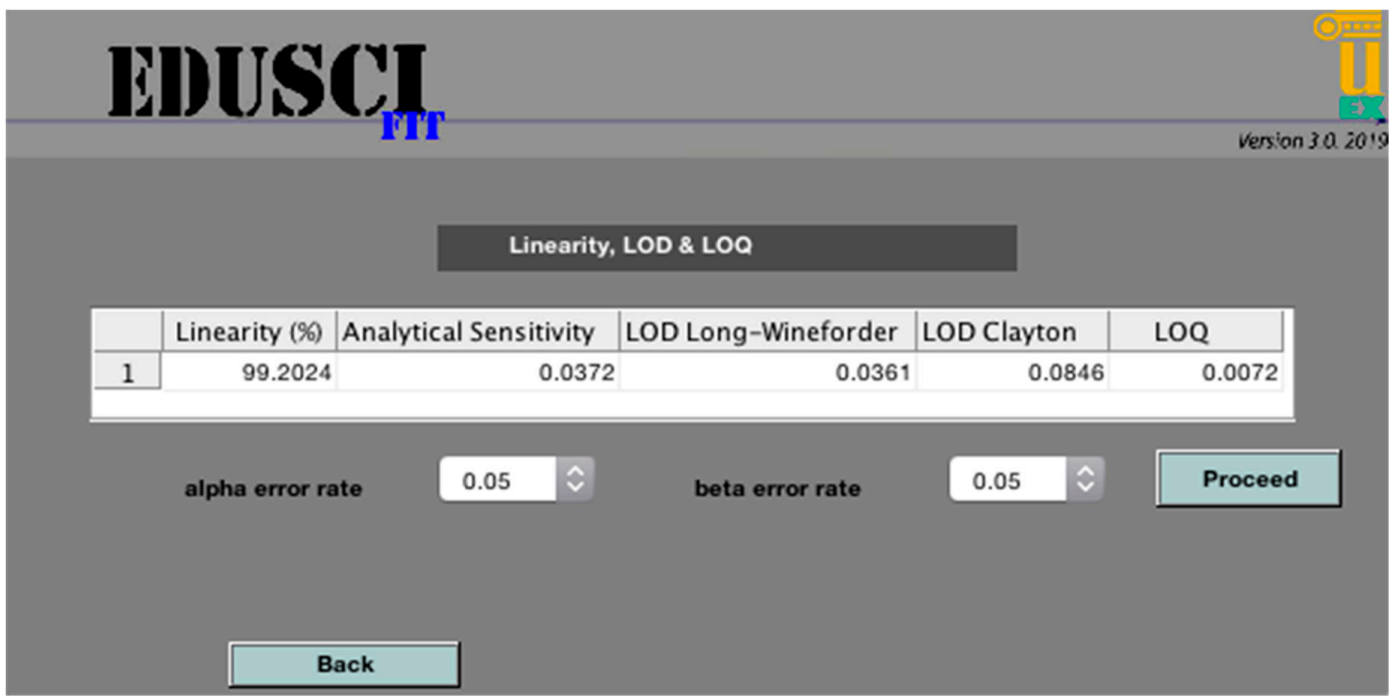

Figure 4. Numerical parameters used to describe the quality of an analytical method: linearity (\%), analytical sensitivity, limit of detection (LOD), and limit of quantification (LOQ). 


\subsection{Numerical and Analytical Tests}

Figure 5 shows a screenshot of the third and final part of the results provided by EdusSciFIT when prediction possibilities of two different methods are compared. To conduct this test, students need to review the experimental data of two different methods and the predictions obtained after their application. Afterwards, the software graphically shows whether both methods are comparable. The prediction possibilities of two different methods are comparable if the blue dot and the green cross are within the elliptical joint confidence region (EJCR). EJCR is displayed at the selected significance level.

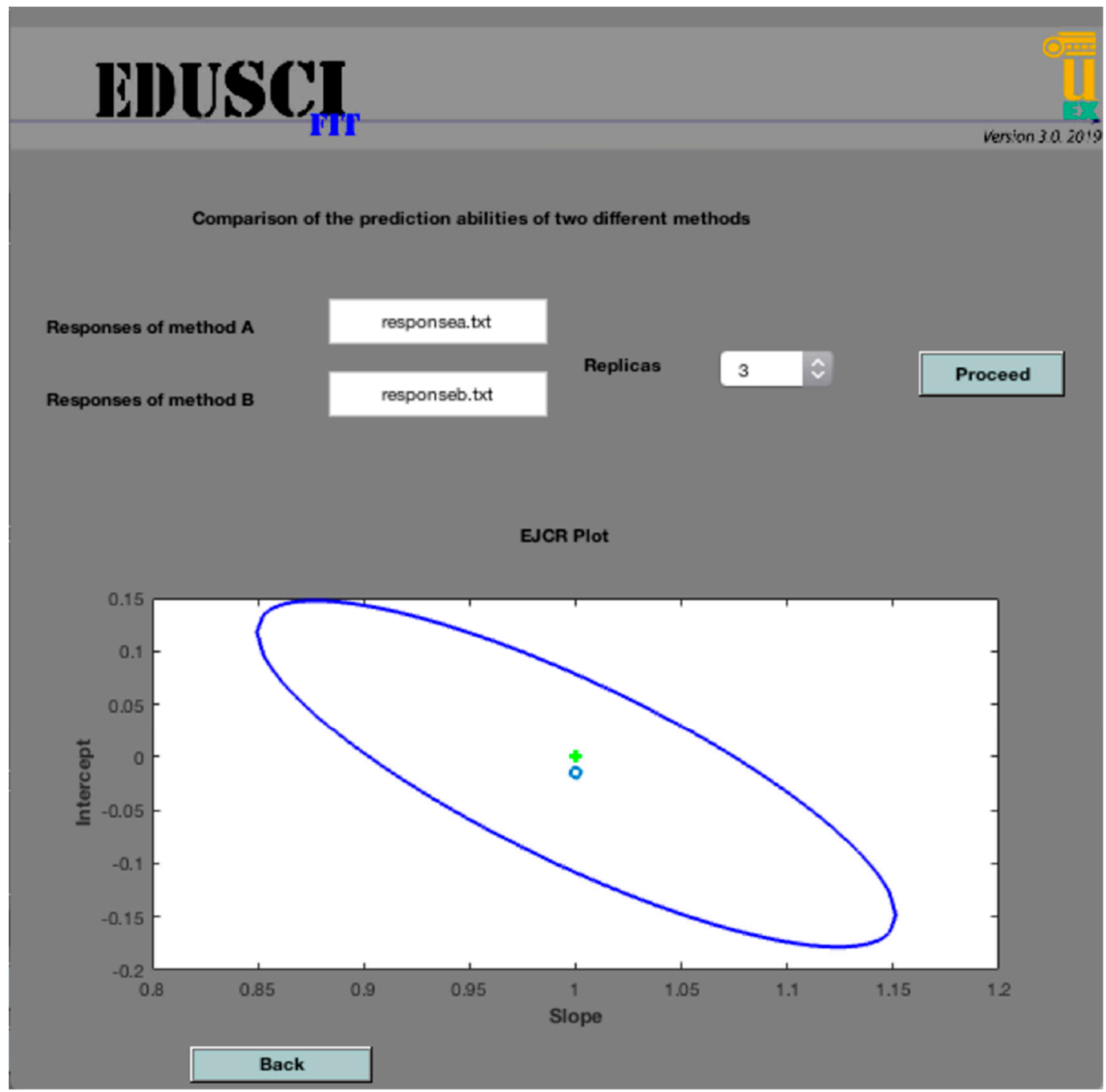

Figure 5. The elliptical joint confidence region (EJCR) plot used to compare the prediction abilities of two different methods.

\subsection{Survey Analysis, Results, and Discussion}

The developed toolbox was assessed by the aforementioned decision-makers. As shown in Table 3, the analyzed sample shows suitability for toolbox integration in a science course. The survey results summarized in Table 3 were organized to show users' perceptions for each one of the different situations the application might offer in screens B and E. Users' perceptions of the main screen of the toolbox is provided in screen A. Screen A, as shown in Figure 1, the main screen toolbox presentation, obtained a score of $45 \%$ very likely ( $86 \%$ positive perception (most likely and likely, $45 \%$ and $41 \%$, respectively). Screen B, the first part of the presentation as shown in Figure 2, obtained a score of 31\% 
very likely with $84 \%$ positive perception (most likely and likely, $31 \%$ and $53 \%$, respectively). Screen C, the second part of the presentation as shown in Figure 3, obtained a score of $29 \%$ very likely with $67 \%$ positive perception (most likely and likely, $29 \%$ and $38 \%$, respectively). Screen D, another second part of the presentation as shown in Figure 4, obtained a score of $39 \%$ very likely with $83 \%$ positive perception (most likely and likely, 39\% and $44 \%$, respectively). Screen E, the fourth and final part of the presentation as shown in Figure 5, obtained a score of 31\% very likely with $84 \%$ positive perception (most likely and likely, 31\% and 53\%m respectively).

Table 3. Likelihood survey analysis according to five different screen sections of SciEduFIT.

\begin{tabular}{|c|c|c|c|c|c|c|}
\hline \multirow{2}{*}{\multicolumn{2}{|c|}{ Five-Point Likert Scale }} & \multicolumn{5}{|c|}{ Screens } \\
\hline & & \multirow{2}{*}{$\frac{\mathbf{A}}{45 \%}$} & \multirow{2}{*}{$\frac{\text { B }}{33 \%}$} & \multirow{2}{*}{$\frac{\mathrm{C}}{29 \%}$} & \multirow{2}{*}{$\frac{\mathbf{D}}{39 \%}$} & \multirow{2}{*}{$\frac{\mathbf{E}}{34 \%}$} \\
\hline 5 & Very likely & & & & & \\
\hline 4 & Likely & $41 \%$ & $42 \%$ & $38 \%$ & $44 \%$ & $43 \%$ \\
\hline 3 & $\begin{array}{l}\text { Not likely, not } \\
\text { unlikely }\end{array}$ & $10 \%$ & $10 \%$ & $15 \%$ & $9 \%$ & $10 \%$ \\
\hline 2 & Unlikely & $1 \%$ & $7 \%$ & $6 \%$ & $3 \%$ & $6 \%$ \\
\hline 1 & Very unlikely & $1 \%$ & $5 \%$ & $6 \%$ & $3 \%$ & $4 \%$ \\
\hline 0 & $\begin{array}{c}\text { Do not } \\
\text { know/blank }\end{array}$ & $2 \%$ & $3 \%$ & $6 \%$ & $2 \%$ & $3 \%$ \\
\hline \multicolumn{2}{|c|}{ Overall evaluation } & 4.22 & 3.82 & 3.68 & 4.07 & 3.88 \\
\hline
\end{tabular}

As shown in Figure 6, according to suitability evaluation from the professionals' survey, we noticed that analyses revealed all proposed and implemented parts were favored by the professionals. Screens $\mathrm{A}$ and D were the most favored, and screen $\mathrm{C}$ was the least favored. Screens B and $\mathrm{E}$ had a difference between users' perception, but the difference was not significant. Therefore, the implemented screens reflected their practical suitability for a blended computer-aided and scaffolding learning toolbox, in terms of usability to reinforce numerical concepts in flipped science education.

The proposed software, EduSciFIT, is suitable for helping to reinforce numerical concepts in flipped science education as a blended computer-aided and scaffolding learning toolbox. The toolbox helps students reinforce the theoretical contents delivered in lectures or clarify material in course textbooks. Also, EduSciFIT can increase their comfort when using commonly used numerical analysis tools and can comprehend the main numerical concepts in science education through self-practice and experimentation, especially when using the laboratory exercises. The proposed tool incorporates the most relevant numerical concepts that are generally used to determine the possible matrix influences or to parallel outcomes from different methods or students. In terms of the suitability evaluation of the toolbox, different patterns generated by the survey analysis showed positive results. Here, the results show an indicator-based model, i.e., the suitability of a computer-aided blended and scaffolding learning toolbox in flipped science education and the efficiency of the five different screens compensating on behalf of their flexible characters. The results summarize the possible problems with traditional education tools, providing options and activities for a computer-aided blended and scaffolding learning toolbox for flipped science education. Also, the toolbox can be used to resolve decision-makings problems, given the proposed toolbox's flexibility and relevance. 

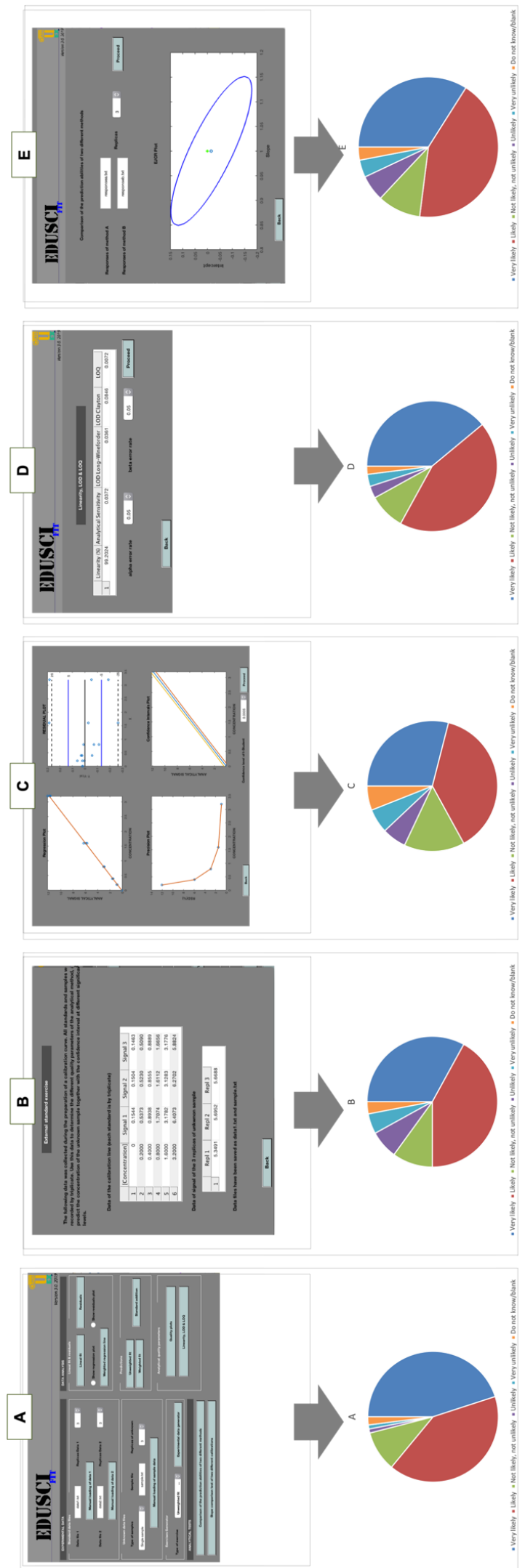

Figure 6. EduSciFIT suitability test of screens A to E. 


\section{Conclusions}

We aimed to describe a computer-based blended and scaffolding learning toolbox to reinforce the numerical concepts taught in flipped science education. The toolbox was used after instruction for a sophomore course of the Primary Education bachelor degree in the Training Teaching School of the University of Extremadura (Spain). We applied this toolbox in scripted laboratory classes after theoretical lectures. Here, students had the chance to practice their observational skills and establish links between theory and practice. Then, with the post-task questionnaire survey, we obtained information and measurements to assess the suitability of toolbox for the class.

We described an ad-hoc MATLAB environment, framed in Adobe Captivate 6 as am HTML5-based e-learning application, that can be used for a laboratory session. This toolbox provides students with a useful tool that allows them to understand the main numerical concepts in science education through self-practice and experimentation. This toolbox, named EduSciFIT, is a blended and scaffolding learning system. It incorporates the most relevant numerical concepts that are generally used to determine possible matrix influences or to parallel the outcomes from different methods or students. The results of the professionals' survey revealed that the example is extremely consistent and appropriate. On the basis of the suitability evaluation in the professionals' survey, we discovered that all parts proposed and implemented are favored. With a five-point Likert scale, these results were also supported by 43 survey-responders. We tested four different sections and overall presentation (A to E). Screens $\mathrm{A}$ and $D$ were the most favored, and screen $C$ was the least favored. Screens B and $E$ had a non-significant difference among the users' perception.

By using this tool, students can acquire the skills to establish numerical and analytical methods in flipped science education. To investigate how and to what extent students would benefit from applying new toolbox in laboratory exercises, a survey was conducted to measure the suitability of the proposed toolbox. The positive results of the professionals' survey supports the introduction of novel software other than what is currently being used in the area of flipped science education. Although the results from this study allowed us to confirm the potential of the toolbox's usability in flipped science education, this study should be considered an initial step and more extensive class data and user considerations should be incorporated into future study.

Author Contributions: Conceptualization, D.G.-G. and J.S.J.; methodology, D.G.-G. and J.S.J.; software, D.G.-G. and J.S.J.; validation, D.G.-G. and J.S.J.; formal analysis, D.G.-G. and J.S.J.; investigation, D.G.-G. and J.S.J.; resources, D.G.-G. and J.S.J.; data curation, D.G.-G. and J.S.J.; writing-original draft preparation, D.G.-G. and J.S.J.; writing—review and editing, D.G.-G. and J.S.J.; visualization, D.G.-G. and J.S.J.; supervision, D.G.-G. and J.S.J.; project administration, D.G.-G. and J.S.J.

Funding: This research was funded by Consejerería de Economía e Infraestructura y Fondo Social Europeo (Projects IB18004 and GR18004) and Project EDU2016-77007-R (AEI/FEDER, UE) of the Ministry of Science, Innovation and Universities of Spain.

Conflicts of Interest: The authors declare no conflict of interest.

\section{References}

1. Linn, M.C.; Clark, D.; Slotta, J.D. WISE design for knowledge integration. Sci. Educ. 2003, 87, 517-538. [CrossRef]

2. Roschelle, J.M.; Pea, R.D.; Hoadley, C.M.; Gordin, D.N.; Means, B.M. Changing how and what children learn in school with computer-based technologies. Future Child 2000, 10, 76-101. [CrossRef]

3. González-Gómez, G.; Jeong, J.S.; Airado Rodríguez, D.; Cañada-Cañada, F. Performance and perception in the flipped learning model: An initial approach to evaluate the effectiveness of a new teaching methodology in a general science classroom. J. Sci. Educ. Technol. 2016, 25, 450-459. [CrossRef]

4. Kuiper, E.; Volman, M.; Terwel, J. Developing Web literacy in collaborative inquiry activities. Comput. Educ. 2009, 52, 668-680. [CrossRef] 
5. González-Gómez, D.; Airado Rodríguez, D.; Cañada-Cañada, F.; Jeong, J.S. A comprehensive application to assist in acid-base titration self-learning: An approach for high school and undergraduate students. J. Chem. Educ. 2015, 92, 855-863. [CrossRef]

6. Steyn, M.D.V.; Alexander, P.M.; Röhm, D. CAL for first year analytical chemistry by distance education. Comput. Educ. 1996, 27, 95-101.

7. Cingi, C.C. Computer aided education. Procedia Soc. Behav. Sci. 2013, 103, 220-229. [CrossRef]

8. Heck, B.S.; Poindexter, S.E.; Garcia, R. Integrating the web into traditional teaching methods. In Proceedings of the American Control Conference, Chicago, IL, USA, 28-30 June 2000.

9. Jeong, J.S.; Ramírez-Góomez, Á. Development of a web graphic model with fuzzy-Decision-Making Trial and Evaluation Laboratory/Multi-Criteria-Spatial Decision Support System (F-DEMATEL/MC-SDSS) for sustainable planning and construction of rural housings. J. Clean. Prod. 2018, 199, 584-592. [CrossRef]

10. Jeong, J.S.; González-Gómez, D.; Cañada-Cañada, F. The study of flipped-classroom for pre-service science teachers. Educ. Sci. 2018, 8,1-11. [CrossRef]

11. Espinosa Manasilla, A.; Muñoz de la Peña, A.; Cañada Cañada, F.; Bohoyo Gil, D.; Gonzalez Gómez, D. Analytical chemistry computational experiments. An educational kenetic study using Matlab programming. Chem. Educ. 2007, 12, 190-195.

12. Jeong, J.S.; González-Gómez, D.; Cañada-Cañada, F.; Gallego-Picó, A.; Carlos Bravo, J. Effects of active learning methodologies on the students' emotions, self-efficacy beliefs and learning outcomes in a science distance learning course. J. Technol. Sci. Educ. 2019, 9, 217-227. [CrossRef]

13. Jeong, J.S.; González-Gómez, D.; Cañada-Cañada, F. Students' perceptions and emotions toward learning in a flipped general science classroom. J. Sci. Educ. Technol. 2016, 25, 747-758. [CrossRef]

14. Sánchez-Martín, J.; Zamora-Polo, F.; Moreno-Losada, J.; Parejo-Ayuso, J.P. Innovative education tools for developing ethical skills in university science lessons. The case of the moral cross dilemma. Ramon Llull J. Appl. Ethics 2017, 8, 225-245.

15. Larreamendy-Joerns, J.; Leinhardt, G. Going the distance with online education. Rev. Educ. Res. 2006, 76, 567-605. [CrossRef]

16. Tallent-Runnels, M.K.; Thomas, J.A.; Lan, W.Y.; Cooper, S.; Ahern, T.C.; Shaw, S.M. Teaching courses online: A review of the research. Rev. Educ. Res. 2006, 76, 93-135. [CrossRef]

17. Stockwell, B.R.; Stockwell, M.S.; Cennamo, M.; Jiang, E. Blended learning improves science education. Cell 2015, 162, 933-936. [CrossRef] [PubMed]

18. Vygotsky, L. Mind in Society; Harvard University Press: London, UK, 1978.

19. Harrison, N. Using the interactive whiteboard to scaffold a metalanguage: Teaching higher order thinking skills in preservice teacher education. Austral. J. Educ. Technol. 2013, 29, 54-65. [CrossRef]

20. González-Gómez, D.; Jeong, J.S.; Cañada-Cañada, F.; Gallego Picó, A. La enseñanza de contenidos científicos a través de un modelo «Flipped»: Propuesta de instrucción para estudiantes del Grado de Educación Primaria. Enseñanzade las Ciencias 2017, 35, 71-87.

21. Jeong, J.S.; Ramírez-Gómez, Á.; González-Gómez, D. A web-based scaffolding-learning tool for design students' sustainable spatial planning. Archit. Eng. Des. Manag. 2017, 13, 262-277. [CrossRef]

22. Oosterhof, A.; Conrad, R.M.; Ely, D.P. Assessing Learners Online; Pearson: New York, NY, USA, 2008.

23. Zawilinski, L.M.; Richard, K.A.; Henry, L.A. Inverting instruction in literacy methods courses: Making learning more active and personalized. J. Adolesc. Adult Lit. 2016, 59, 695-708. [CrossRef]

24. Butt, A. Student views on the use of a flipped classroom approach: Evidence from Australia. Bus. Educ. Acredit. 2014, 6, 33-43.

25. Tucker, B. The Flipped classroom. Online instruction at home frees class for learning. Educ. Next 2012, 12, 82-83.

26. Munir, M.T.; Baroutian, S.; Young, B.R.; Carter, S. Flipped classroom with cooperative learning as a cornerstone. Educ. Chem. Eng. 2018, 23, 25-33. [CrossRef]

27. Hill, J.R.; Song, L.; West, R.E. Social learning theory and web-based learning environments: A review of research and discussion of implications. Am. J. Distance Educ. 2009, 23, 88-103. [CrossRef]

28. Tourón, J.; Santiago, R. Flipped learning model and the development of talent at school. Rev. Educ. 2015, 368, 33-65.

29. Moraros, J.; Islam, A.; Yu, S.; Banow, R.; Schindelka, B. Flipping for success: Evaluating the effectiveness of a novel teaching approach in a graduate level setting. BMC Med. Educ. 2015, 15, 1-10. [CrossRef] [PubMed] 
30. Mohamed, H.; Lamina, M. Implementing flipped classroom that used an intelligent tutoring system into learning process. Comput. Educ. 2018, 124, 62-76. [CrossRef]

31. Bull, G.; Ferster, B.; Kjellstrom, W. Inventing the flipped classroom. Learn. Technol. 2012, 40, 10-11.

32. Strayer, J.F. How learning in an inverted classroom influences cooperation, innovation and task orientation. Learn. Environ. Res. 2012, 15, 171-193. [CrossRef]

33. Rutten, N.; van Joolingen, W.R.; van der Veen, J.T. The learning effects of computer simulations in science education. Comput. Educ. 2012, 58, 136-153. [CrossRef]

34. Massart, D.L.; Vandeginste, B.G.M.; Buydens, L.M.C.; De Jong, S.; Lewi, P.J.; Smeyers-Verbeke, J. Handbook of Chemometrics and Qualimetrics: Part A; Elsevier: Amsterdam, The Netherlands, 1997.

35. Miller, N.J.; Miller, J.C. Statistics and Chemometrics for Analytical Chemistry; Prentice Hall: London, UK, 2000.

(C) 2019 by the authors. Licensee MDPI, Basel, Switzerland. This article is an open access article distributed under the terms and conditions of the Creative Commons Attribution (CC BY) license (http://creativecommons.org/licenses/by/4.0/). 